\title{
Estratégias de gênero em contexto diaspórico: o caso dos missionários pentecostais brasileiros em Barcelona
}

\author{
Gender strategies in a diasporic context: \\ the case of the Brazilian Pentecostal Missionaries in Barcelona
}

\author{
Donizete Rodrigues* \\ Marcos de Araújo Silva**
}

\begin{abstract}
Resumo
O reavivamento religioso do 'Norte' (Europa), desenvolvido por missionários pentecostais do 'Sul' (América Latina - Brasil, em particular), no contexto da denominada 'reverse mission', é um processo dinâmico e em forte expansão. A partir de uma etnografia localizada - realizada entre novembro de 2011 e abril de 2012 - este artigo analisa o trabalho de evangelização e as estratégias de gênero que são desenvolvidas por dois emblemáticos e diferenciados movimentos religiosos neopentecostais brasileiros que actuam na área metropolitana de Barcelona, Espanha: a evangélica e transnacionalizada Igreja Universal do Reino de Deus e o grupo católico-carismático Raboni Ajaray. Com base num estudo antropológico comparativo do cotidiano destes dois grupos de fiéis, discutimos como um caráter "feminilizado" e outro "masculinizado", respectivamente, definem importantes fronteiras entre os católicos e os evangélicos analisados. Os dados etnográficos demonstram como certas particularidades dos imigrantes podem atuar como uma fonte de diferenciação social que fomenta oportunidades e estratégias doutrinais específicas para homens e mulheres, em um contexto de diáspora.
\end{abstract}

Palavras-chave: migração; missionários brasileiros; gênero; Pentecostalismo; Barcelona.

\begin{abstract}
The religious revival of the 'North' (Europe), developed by Pentecostal missionaries of the 'South' (Latin America - Brazil, in particular), in the context of the 'reverse mission', is a dynamic process and in significant expansion. From a localized ethnography - conducted between November 2011 and April 2012 - this article analyzes the work of evangelization and gender strategies developed by two emblematic and differentiated Brazilian neo-Pentecostal religious movements, in the metropolitan area of Barcelona (Spain): the evangelical and transnationalised Universal Church of the Kingdom of God and the Catholic Charismatic Renewal group Raboni Ajaray. From a comparative anthropological study of the daily life of these two religious groups, we discuss how a "feminized" and "manly" character, respectively, define important boundaries between Catholics and evangelicals. The ethnographic data demonstrate how certain characteristics of immigrants can act as a source of social differentiation that fosters opportunities and specific doctrinal strategies for men and women, in a context of diaspora.
\end{abstract}

Keywords: migration; Brazilian missionaries; gender; Pentecostalism; Barcelona.

\footnotetext{
Artigo recebido em: 06 de janeiro de 2015 e aprovado em 28 de setembro

* Professor Associado em Antropologia com Agregação em Sociologia da Universidade da Beira Interior e Investigador-Sênior do CRIACentro em Rede de Investigação em Antropologia, Portugal. País de origem: Brasil. E.mail: donizetti.rodrigues@gmail.com.

** Doutor em Antropologia, Professor Colaborador e Pesquisador de Pós-Doutorado do Programa de Pós-Graduação em Sociologia (PPGS) da UFPE. País de Origem: Brasil. E mail: marcosimonstock@gmail.com
} 


\section{Introdução}

O processo de globalização e os massivos fluxos migratórios transcontinentais de pessoas provocam, nas sociedades contemporâneas, significativas mudanças sociais, culturais, étnicas, religiosas e identitárias (YANG; EBAUGH, 2001) e estes novos pluralismos culturais afetam também as estratégias e relações de gênero, no contexto das comunidades de imigrantes e também entre os nacionais (PLUSS, 2009).

Os estudos sociológicos e antropológicos sobre migração transnacional e religião comprovam que a adesão e a participação em atividades religiosas é muito importante para a população imigrante (PÉREZ-AGOTE, 2010). No contexto da diáspora, além do apoio espiritual, a religião proporciona valores positivos, maior integração social e um forte sentimento de pertença e manutenção da identidade. Além disso, há fatores que podemos denominar de 'solidariedade pragmática', ou seja, atividades que ajudam na consecução de moradia, emprego, educação formal, acesso à saúde e apoio judiciário para os ilegais/indocumentados. As instituições religiosas são lugares/pontos de encontro onde os imigrantes encontram compatriotas e outros imigrantes na mesma situação econômica, social e jurídica. Os locais de culto promovem não só eventos estritamente litúrgicos, mas facilitam, também, a interação social dos recém-chegados e a difusão de informações, perspectivas e possibilidades nas mais diversas esferas sociais.

O fenômeno do neopentecostalismo, protestante e católico, surgiu nos Estados Unidos, na década de 1960, e rapidamente se expandiu para diferentes partes do mundo, nomeadamente para a América Latina, com grande destaque para o Brasil. Em consequência disso, o neopentecostalismo é hoje um dos maiores movimentos religiosos do planeta (COLEMAN, 2000) e o Brasil o país com a maior concentração de pentecostais do mundo (FRESTON, 2010).

Considerando que o Brasil é um dos principais exportadores de movimentos religiosos para a Europa (VELHO, 2009), este artigo analisa o trabalho de 
evangelização e as estratégias de gênero que são desenvolvidas por dois emblemáticos e diferenciados grupos de missionários pentecostais brasileiros em Barcelona, uma região historicamente considerada como a mais secular e anticlerical da Espanha (LÓPEZ; CORTINA, 1998): a evangélica e transnacionalizada Igreja Universal do Reino de Deus (IURD) e o grupo carismático católico Raboni Ajaray (SILVA; RODRIGUES, 2013). Essa evangelização na diáspora pode ser interpretada dentro da perspectiva analítica da 'missão invertida'; o Brasil, anteriormente evangelizado por europeus, no contexto do colonialismo, hoje envia missionários (católicos e evangélicos) para a Europa com a "missão divina" de "recristianizar" este continente, que sofre um processo de secularização (FRESTON, 2010).

A etnografia em Barcelona ocorreu entre novembro de 2011 e abril de 2012. Sendo constituído por pessoas mais "abertas", os membros do Raboni Ajaray sabiam que nós éramos etnógrafos. Contudo, em virtude das dificuldades de se fazer pesquisas de campo entre os membros da IURD, e especialmente com os seus líderes, nós nos identificávamos como imigrantes brasileiros que queriam frequentar e participar nas actividades desta Igreja. Em ambos os grupos, o método etnográfico utilizado foi a observação participante em vários eventos sociais e religiosos e conversas informais com diversos/as fiéis e interlocutoreschave'.

\section{Pentecostalismo Protestante e Católico na Espanha}

A Espanha, historicamente, tem sido um país de emigrantes. Nas últimas três décadas, porém, começou a receber grandes fluxos de imigração: de 2\% em

\footnotetext{
${ }^{1}$ A fim de preservar as suas identidades, todos os/as interlocutores/as citado/as neste trabalho são apresentados/as com nomes fictícios. A pesquisa etnográfica, com a inserção dos autores no terreno (observação-participante), foi feita seguindo todos os parâmetros éticos exigidos, nomeadamente, a permissão/autorização, das lideranças e dos interlocutors dos movimentos religiosos em estudo, para registar as informações em áudio, vídeo, fotos, com a identificação das pessoas.
} 
1990, a porcentagem de estrangeiros residentes passou para mais de $11 \%$ da população total de 46 milhões de pessoas em 2010 (FUENTES; CALLEJO, 2011). Como consequência da imigração transnacional, ocorreu uma significativa transformação nos cenários étnicos, religiosos e culturais do país. Apesar desses processos de mudança, a maioria da população espanhola ainda é católica $(73,5 \%)$; no entanto, os imigrantes católicos são uma minoria e o número de evangélicos tem aumentado significativamente (SANTIAGO, 2010; PÉREZ-AGOTE, 2010). Segundo Velasco (2012), atualmente 72\% dos imigrantes que vivem no território espanhol se declaram cristãos e, deste conjunto, 58\% é composto por evangélicos, $30 \%$ é composto por católicos ligados à Igreja Apostólica Romana e 12\% são católicos ortodoxos, maronitas ou coptas.

O pentecostalismo chegou à Espanha em 1923, trazido por missionários suecos, mas cresceu muito lentamente e encontrou muitas dificuldades para atingir a população católica espanhola. Contudo, devido à migração transnacional, a Espanha recentemente passou a ter diversas denominações pentecostais (católicas e protestantes) fundadas por missionários da América Latina, em particular do Brasil (MacHARG, 2008).

A IURD foi fundada no Brasil, em 1977, pelo então pastor Edir Macedo. Hoje é o exemplo de maior sucesso da expansão neopentecostal brasileira e está presente nos cinco continentes e em mais de 180 países. Na Espanha, ela adota o nome de "Família Unida" e na cidade de Barcelona, durante o período em que desenvolvemos pesquisas de campo, ela tinha três templos e um grupo de oração. Segundo o site oficial “Arca Universal”, a IURD está presente na Espanha desde 1990 e suas atividades no país começaram nas cidades de Madri e Barcelona (LA UNIVERSAL, 2015). 
Figura 1: Distribuição espacial dos templos da IURD-Família Unida.

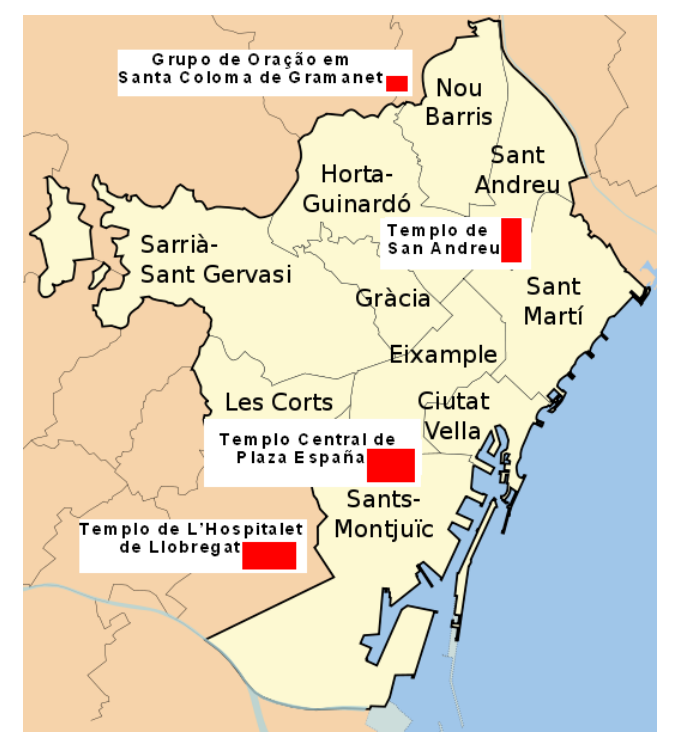

Fonte: Mapa adaptado da cidade de Barcelona.

Com relação à divisão do trabalho entre pastores e obreiros/as, apenas os pastores se dedicam exclusivamente à Igreja e recebem uma remuneração mensal por este trabalho. Já os/as obreiros/as tentam conciliar os seus trabalhos (as mulheres normalmente atuam como babás, faxineiras e cuidadoras de idosos) com o serviço missionário e voluntário na Família Unida.

Em Barcelona, os fiéis, em especial os obreiros, possuem atividades nos templos durante todos os dias da semana, seguindo um calendário de reuniões (todas executadas em língua castelhana), assim distribuído: 


\begin{tabular}{|c|c|}
\hline DIA & TIPO DE REUNIÃO E HORÁRIO \\
\hline Segunda-Feira & Reunião da Prosperidade Econômica, às 07:00, 16:00 e 20:00. \\
\hline Terça-Feira & Reunião da Restauração da Saúde, às 07:00, 16:00 e 20:00. \\
\hline Quarta-Feira & Reunião de Recebimento do Espírito Santo, às 07:00, 16:00 e 20:00. \\
\hline Quinta-Feira & Evangelização pelas ruas de Barcelona e cidades vizinhas. \\
\hline Sexta-Feira & Sessão Espiritual do Descarrego, às 07:00, 16:00 e 20:00. \\
\hline Sábado & Terapia do Amor no Templo Central, às 18:00. \\
\hline Domingo & Reunião das Famílias, às 09:30, e Reunião de Clamor, às 16 e 18hs. ${ }^{2}$ \\
\hline
\end{tabular}

Além do Templo de San Andreu e do Templo Central de Plaza España espaços centrais privilegiados da nossa pesquisa etnográfica - também foram feitos trabalhos de campo no templo IURD-Familia Unida do Hospitalet de Llobregat e no Grupo de Oração que esta igreja abriu em Santa Coloma de Gramenet. 3

Como pudemos verificar no terreno, mais de $90 \%$ dos fiéis dos templos da Familia Unida é composto por imigrantes sul-americanos (em especial equatorianos, colombianos, bolivianos e brasileiros) e africanos. Com base nas nossas pesquisas em Barcelona - e também em Madri - podemos afirmar que tais percentuais se devem ao fato desta instituição religiosa tentar projetar-se como uma igreja "universal", "não-étnica" e "não-imigrante". No entanto, em Espanha, a IURD-Família Unida ainda não conseguiu desenvolver estratégias que dissociem sua imagem das outras "igrejas étnicas" da cidade e por isso, ela comumente costuma ser percebida, tanto pelos seus fieis e visitantes, quanto pelo restante da

\footnotetext{
2 Estas "reuniões de clamor" visam solucionar problemas específicos dos fiéis, tais como envolvimento de filhos com as drogas, problemas no casamento, etc. São destinadas às mulheres em geral e às que possuem filhos considerados "problemáticos", em particular. Na nossa etnografia participámos em quatro destas reuniões na Espanha e de outras duas na Itália; estas reuniões, por serem voltadas para resolver problemas que envolviam jovens (como envolvimento com drogas e "desobediência"), foram intituladas de "Clamor das mães aflitas".

${ }^{3}$ Hospitalet de Llobregat e Santa Coloma de Gramenet são municípios que integram o chamado "cinturão industrial" da região metropolitana de Barcelona.
} 
população barcelonesa em geral, como uma igreja "brasileira" ou como uma igreja "sudaca"4

O grupo católico-carismático Raboni Ajaray foi criado no ano de 2007 por um grupo de 14 imigrantes brasileiros que viviam no município de Santa Coloma de Gramenet. Identificados com a vertente carismática do catolicismo romano, decidiram se reunir periodicamente na paróquia San Juan Bautista, num espaço cedido pelo então padre responsável pelo local. Após o início de suas atividades religiosas (encontros de louvor e adoração), o Raboni Ajaray passou a atrair também católicos catalães.

Com o passar do tempo, este grupo, por sua vez, passou a apresentar uma situação muito diferente da IURD-Família Unida. A grande maioria dos fiéis é catalã, com somente alguns espanhóis nascidos fora da Catalunha. Os imigrantes são minoria, com aproximadamente 15\% do total de fiéis, compondo um grupo de dez pessoas: quatro casais heterossexuais brasileiros e um cubano. Embora eles se identifiquem como missionários, durante a semana eles desenvolvem trabalhos paralelos: engenheiros (três homens), um técnico de som (um homem), recepcionistas de hotel (duas mulheres e um homem) e atendentes de lojas (três mulheres). Eles dedicam os seus finais de semana e feriados às atividades religiosas. O grupo se encontra duas vezes por mês na paróquia San Juan Bautista (Santa Coloma de Gramenet) e uma vez por mês eles animam os "Encuentros de Alabanza, Adoración y Sanación" - EAAS (Encontros de Louvor, Adoração e Cura), que ocorrem na paróquia San Genís dels Agudells (no bairro barcelonês de Vall D'Hebron).

Considerando a composição dos “públicos” (fiéis), a dimensão do gênero adquire, neste contexto, uma significativa importância: ambos os grupos religiosos

\footnotetext{
${ }^{4} \mathrm{Na}$ Espanha, "sudaca" é um termo pejorativo utilizado para se referir a pessoas, instituições ou estabelecimentos comerciais de origem sul-americana.
} 
podem ser considerados "feminilizados", pois a presença de mulheres é de aproximadamente 60\% no Raboni Ajaray e de 70\% na Família Unida.

O Raboni Ajaray se identifica como um grupo "carismático e mariano”, onde a intercessão da Virgem Maria é tida como imprescindível para a consecução das graças espirituais por meio de recebimento do "fogo do Espírito santo" (Pentecostes). Já na IURD-Família Unida, a doutrina e o cotidiano litúrgico se centram na figura de Jesus Cristo e na resolução de problemas físicos, econômicos e espirituais, através de exorcismos e "correntes de libertação". No entanto, embora apresentem estas citadas diferenças do ponto de vista religioso, estes dois grupos (católico-carismático e protestante-evangélico) possuem algumas similaridades:

a) Os fiéis se referem às suas vidas passadas, à época em que ainda não haviam começado a frequentar as atividades religiosas de cada grupo, com a expressão "quando eu era do mundo". O termo "mundo" aqui se refere a tudo aquilo que não faz parte do Espírito Santo e nem dos ensinamentos de Jesus Cristo, ou seja, qualquer comportamento considerado mundano ou pecaminoso. De acordo com os/as interlocutores/as, carismáticos/as e evangélicos/as, os seus respectivos grupos religiosos trouxeram "coisas boas" para suas vidas, tais como contatos e possibilidades de emprego, trabalho informal e negócios - que são "eficazes" por fazerem com que eles/as possam "viver no mundo sem fazer parte dele”, isto é, "puros e não-corrompidos” em uma cidade "pagã” como Barcelona.

2) Cerca de $40 \%$ dos fiéis carismáticos disseram que já foram vinculados ou já haviam participado, no passado, de rituais aos quais hoje chamam de "bruxaria", "feitiçaria", "macumbaria" e "xamanismo". Já entre os evangélicos, este percentual sobe para $80 \%$; este aspecto é antropologicamente relevante, pois ajuda na compreensão de como as sincréticas liturgias da IURD podem atrair e converter um público tão heterogêneo do ponto de vista religioso. Os pastores reproduzem 
rituais que condenam em outras religiões (de modo que os fiéis não percebam) e conseguem atrair e converter um público tão diversificado, como é o seu em Barcelona, transmitindo a sensação de eficácia simbólica e de bem-estar social aos fiéis como consequência das suas práticas litúrgicas e ritualísticas.

A sensação de bem-estar social também deriva dos trabalhos sociais que a IURD promove e que costumam fomentar nos seus fiéis sentimentos como gratidão e dívida que se coadunam com os circuitos predominantes de dádiva (MAUSS, 1974), ou seja, os circuitos de dádiva caritativa, amical e/ou clientelista. Os trabalhos sociais abrangem: visitas que objetivam "levar a palavra de Deus" a idosos, enfermos e famílias consideradas "desamparadas" e, principalmente, doações de alimentos, remédios, roupas, muletas e cadeiras de rodas. Vale salientar que a maior parte destas doações provém dos próprios fieis, ou seja, a IURD muitas vezes atua como mera intermediadora entre os fieis que fazem as doações e os necessitados.

\section{0 "feminilizado" Raboni Ajaray}

Em 2008, um pequeno grupo de oração carismático católico começou informalmente com encontros nas casas dos 25 participantes iniciais. Desde fevereiro de 2009, eles se reuniam, uma vez por mês, em uma paróquia da área de "Glòries" (distrito barcelonês). A denominada "Missa Brasil" era celebrada pelo padre brasileiro Renato Fraga. Com o retorno do padre Renato ao Brasil, em dezembro de 2011, estas missas acabaram.

Em junho de 2011, no entanto, o grupo recebeu a "benção" e o respaldo do padre Francesc Espinar, da Paróquia San Juan Bautista, de Santa Coloma (cidade 
da área metropolitana de Barcelona) e desde então foi “oficializado”, recebendo o nome de Raboni Ajaray5.

Nanda é uma das líderes fundadoras deste grupo carismático. Desde 2004, ela vive com seu marido brasileiro em Barcelona. Segundo Nanda, o nome Raboni Ajaray simboliza a mensagem que Deus enviou diretamente para ela: "receba-me, através de música e da alegria, onde quer que você esteja. Eu quero que todas as pessoas recebam o meu Espírito”. Portanto, as práticas litúrgicas e doutrinárias do Raboni Ajaray - que é um exemplo dos diversos grupos católicos carismáticos que existem no Brasil e na diáspora brasileira - são focadas na música, no louvor, na adoração e na manifestação do Pentecostes (Espírito Santo).

O grupo passou a fazer seus encontros, duas vezes por mês, na referida paróquia, que é frequentada por catalães, por espanhóis vindos de fora da Catalunha e por imigrantes sul-americanos. Desde 2005, o padre Espinar ajudava imigrantes e antes da crise económica a comunidade imigrante brasileira era bem maior do que nos dias de hoje. Esta mudança ocorreu, principalmente, porque a maioria destes brasileiros trabalhava no setor da construção civil (o mais afetado pela crise), o que fez com que muitos se vissem obrigados a retornar ao Brasil.

Em setembro de 2011, o catalão Pe. Joaquin Climent, responsável pela paróquia de San Genis dels Agudells - localizada no bairro de Val d'Hebron (no município de Barcelona) - foi a um dos encontros do Raboni Ajaray e ficou "encantado" com o grupo e, por isso, convidou os seus oito membros, líderes e músicos, para "animarem" os "Encuentros de Alabanza, Adoración y Sanación” que, desde 2007, ocorrem uma vez por mês na sua paróquia. Assim, desde 20 de novembro de 2011, no terceiro domingo de cada mês, ocorre na paróquia San Genis dels Agudells estes encontros carismáticos, que costumam atrair, em média, mais de 100 pessoas: mais de 70\% são catalães e espanhóis (que nasceram fora da

\footnotetext{
${ }^{5}$ Raboni é uma palavra aramaica que significa "mestre" e Ajaray uma palavra árabe que significa, literalmente, "venham atrás de mim, façam como eu faço".
} 
Catalunha), o restante do público é composto por brasileiros, colombianos, senegaleses e romenos.

Os encontros animados pelo Raboni Ajaray na paróquia de San Juan Bautista possuem uma participação média de 20 a 30 pessoas, a maioria catalãs e espanholas nascidas em outras regiões; os imigrantes constituem, portanto, uma minoria. No entanto, no que se refere à liderança, o cenário é invertido: missionários/as da América Latina (sob a liderança de mulheres imigrantes) estão “animando", reavivando espiritualmente o catolicismo destes "nativos” europeus.

A ritualidade consiste em músicas, orações, louvores e manifestações do Espírito Santo. A evidência maior destas características litúrgicas é quando o padre Climent, em estado de profunda espiritualidade, faz orações com a mão direita sobre a cabeça dos fiéis. Depois de receber tais orações, algumas pessoas costumam “descansar no Espírito” (ver figura 2).

Figura 2: fiel "descansando no Espírito" (Paróquia San Genís dels Agudells, 26 de fevereiro de 2012)

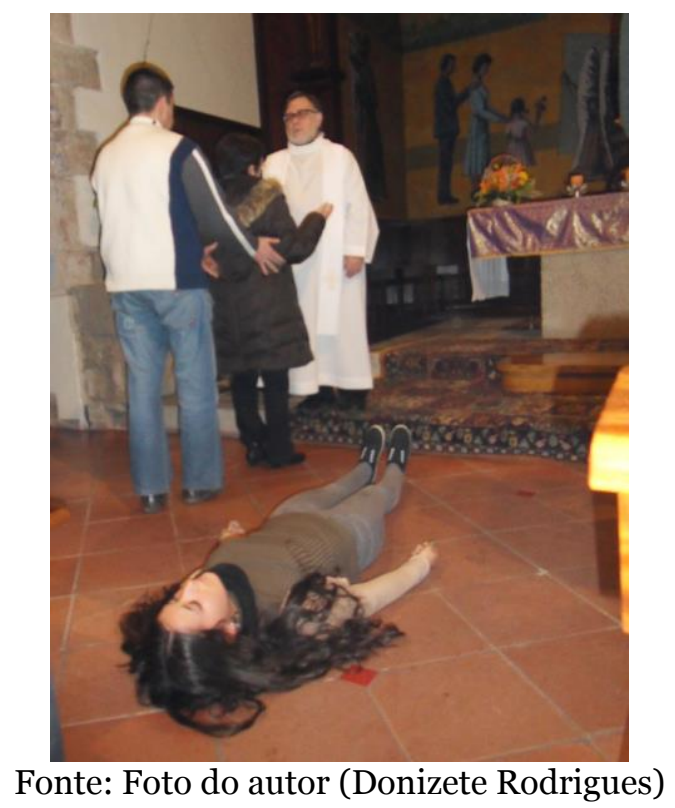


De acordo com os fiéis, homens e mulheres que passaram pela experiência de "descansar no Espírito", trata-se de um momento de profunda espiritualidade, descrito como "sublime", "suave" e "maternal". Receber o Espírito Santo significa também ser "curado", "tocado por Ele" ou de "estar com Ele".

Numa perspectiva comparativa do gênero, a experiência religiosa de "descansar no Espírito" (após receber uma breve oração particular do padre, acompanhada de um toque de suas mãos no rosto) configura uma diferença substancial entre os católicos carismáticos dos "Encontros de Louvor, Adoração e Cura" e os rituais da evangélica Família Unida (que serão melhor descritos no próximo tópico): enquanto os elementos carismáticos são vistos pelos fiéis como "feminilizado" (leve, sublime, maternal), na Família Unida, pelo contrário, o foco são os ardentes "clamores" pelo Espírito Santo e fortes sessões de exorcismo; ritualidades tipicamente "iurdianas" que são percebidas pela maioria dos/as fiéis como um reflexo da "força", do "poder" e do caráter "viril" desta "masculinizada" igreja.

Um ponto a ser salientado é que o padre Climent é reconhecido com um "rebelde" pelos outros padres catalães. Isso pode ser explicado devido ao fato do catolicismo na Catalunha ser dividido em duas principais correntes que, embora dialoguem umas com as outras, diferem substancialmente em termos doutrinários: os carismáticos e os neocatecumenais. Os fiéis ligados ao Caminho Neocatecumenal, um movimento com um caráter "duro" e "masculino", geralmente não aprovam os trabalhos da corrente carismática (BLÁZQUEZ, 2009). Estas divergências internas se refletem nas estratégias de gênero desenvolvidas pelo Raboni Ajaray, que é considerado "feminilizado" e "excessivamente festivo". Com isso, a noção de alteridade religiosa (KEATEN; SOUKUP, 2009) é percebida pelos carismáticos não apenas em relação aos evangélicos, que são também pentecostais, mas particularmente em relação à corrente católica neocatecumenal.

É pertinente aqui a história de um fiel, um admirador do Raboni Ajaray e participante dos encontros da paróquia de San Genis. Hernandez disse que "não 
encontrava espaço” para praticar sua fé no Caminho Neocatecumenal e defende enfaticamente o movimento católico carismático. Ele considera este movimento "leve" e "inclusivo", que respeita as diversidades étnicas e de gênero que fazem parte das sociedades contemporâneas.

De acordo com quatro fiéis que participam nos encontros do grupo Raboni Ajaray (uma catalã, duas espanholas nascidas em Estremadura e um senegalês), os missionários brasileiros são muito "acolhedores e animados". Este fator faz com que mais facilmente os fiéis consigam "se soltar" para expressarem sua fé "com alegria" e, acima de tudo, respeitando e "sabendo dialogar" com a "cultura religiosa tradicional catalã"; cultura religiosa esta que é vista como profundamente influenciada por um catolicismo adjetivado de "popular" e no qual a figura da Virgem Maria ocupa uma posição de destaque. A postura "maternal” do padre Climent, a liderança feminina do Raboni Ajaray, aliadas à percepção de que a cultura brasileira é “aberta”, fazem com que os participantes dos encontros sintam que estão sendo tratados com “cuidado e dedicação”, de uma forma que só mães e mulheres que receberam o Pentecostes saberiam fazer.

A figura da Virgem Maria e suas diferentes manifestações - como a Virgem de Guadalupe (México), Nossa Senhora de Fátima (Portugal) e Nossa Senhora Aparecida (padroeira do Brasil) - são elementos cruciais que influenciam nas percepções de feminilização que circundam o carismático Raboni Ajaray. Estes elementos se fazem presentes no grupo através de comemorações festivas que o Raboni Ajaray promove regularmente nos dias 12 de dezembro, 13 de maio e 12 de outubro, datas em que são festejadas, respectivamente, as Virgens de Guadalupe, Fátima e Aparecida. Segundo alguns membros do grupo, estas celebrações marianas regulares são muito importantes, pois possuem a função de "reforçar", entre as pessoas que participam dos rituais, a “certeza” de que a Virgem Maria é una, porém possui variados rostos e jamais esquece dos seus filhos, aonde quer 
que eles estejam. Já na Família Unida, diferentemente, a ausência de uma 'Mariologia' explica a ênfase nas representações de "Deus Pai" como um "homem forte" e, como resultado disso, o caráter "masculinizado" desta igreja evangélica.

Como já foi referido, em ambos os grupos religiosos (carismáticos e evangélicos), os membros costumam se referir ao passado com a expressão "quando eu era do mundo" e realçam as mudanças positivas provocadas pelo 'batismo no/do Espírito Santo'. Vejamos alguns exemplos. A católica Lucinda disse que após receber o Pentecostes, em um encontro do Raboni Ajaray, em outubro de 2011, sua vida mudou em todos os sentidos, inclusive na maneira como se vê enquanto brasileira e enquanto mulher; ela não possui filhos (no sentido biológico) e salientou que, na Espanha, virou a "mãe" de sua irmã mais nova. Mesmo não sendo mãe, a católica Senyta acha que o caráter "maternal" está inerente à sua nova identidade enquanto "brasileira carismática", já que o "saber cuidar de um filho" seria uma parte intrínseca da vida das mulheres que vivem essa identidade religiosa, independentemente se são mães biológicas ou não. Por ter engravidado e ter que se dedicar ao seu casamento, Keli cedeu a coordenação do Raboni Ajaray para Solange Milera, uma cubana nascida em 1976 e que se define e é reconhecida pelos outros membros do grupo como sendo uma missionária “de alma brasileira”, tanto que ela fala português fluentemente.

O cotidiano etnográfico que vivenciamos em Barcelona nos permite supor que esta liderança feminina de origem latino-americana em uma terra estrangeira se constituiu e está inserida dentro de uma particular tradição religiosa: segundo diversos católicos catalães com os quais dialogamos, o movimento da Renovação Carismática católica começou a ser popularizado na Catalunha a partir de 1975 (ano do término do Franquismo). O processo de popularização ocorreu e se consolidou devido ao trabalho de lideranças católicas carismáticas femininas oriundas da Itália e da América Latina. Nesse sentido, esta liderança religiosa feminina não costuma encontrar resistências no contexto específico da região metropolitana de Barcelona, principalmente porque ela não constitui um 
fenômeno "novo", mas intrínseco aos processos de desenvolvimento das vertentes carismáticas do catolicismo no território catalão, desde o ano de 1975, ano em que ocorreu a morte do ditador Francisco Franco. Tal fato permitiu uma maior "liberdade religiosa" e possibilitou, entre outras coisas, que "ser carismático" deixasse de ser percebido como algo "marginal" no contexto da religiosidade católica catalã e que grupos com lideranças femininas e estrangeiras fossem vistos com certa naturalidade pela população católica local.

Outra questão importante é a hierarquização étnica-social que existe entre os grupos de imigrantes latino-americanos que vivem em Barcelona: os brasileiros, assim como os cubanos, ocupam uma posição "intermediária”, sem sofrer tanto preconceito quanto os equatorianos e bolivianos, porém são menos aceitos que os argentinos e uruguaios. Segundo Solange, os argentinos e uruguaios são "mais aceitos" por serem maioritariamente brancos. Já os imigrantes brasileiros e cubanos não só são mais "feminilizados” como possuem partes significativas de mulheres atuando na prostituição (BADET SOUZA, 2011), reforçando o estigma social (no sentido preconizado por Goffman, 1963), fazendo com que exista uma forte associação entre "ser brasileira ou cubana” e ser prostituta.

Para Solange, estes fatores fazem com que mulheres missionárias brasileiras e cubanas que atuam em Barcelona, como ela e a Keli, devam ser muito "incisivas" e "dedicadas" ao trabalho de evangelização. Isso porque tal trabalho ultrapassa a esfera religiosa e atinge a esfera social e política, no sentido de ser um instrumento eficaz e poderoso para "relativizar", "dar mais moral" à imagem da mulher brasileira e da mulher cubana e mostrar aos catalães e espanhóis que mulheres como elas são capazes de ações "improváveis", como por exemplo, transmitir de uma maneira original o Cristianismo que, no passado, receberam destes europeus que agora evangelizam. Tais fatores foram comentados por Solange e Keli, durante diversas conversas informais que tivemos, nas quais elas falavam sobre seus cotidianos como mulheres imigrantes e missionárias oriundas da América Latina. 
De acordo com os/as interlocutores/as, o catolicismo carismático tem um jeito "feminilizado" e esta característica atrai satisfatoriamente segmentos da população local catalã. A figura da Virgem Maria é central na maneira como os nacionais se percebem enquanto católicos e vivenciam suas espiritualidades particulares. Assim, um caráter "feminilizado" ou "maternal" ligado à esfera religiosa seria algo intrínseco à cultura ibero-americana e, por isso, imprescindível para fazer com que espanhóis e catalães se sintam "em casa" e "à vontade" em um grupo religioso liderado por imigrantes.

Nanda disse que alguns catalães - que participam dos encontros do Raboni Ajaray nas duas paróquias em que ela atua - relataram que se sentiram "estrangeiros" quando visitaram algumas igrejas evangélicas, pois estas não respeitavam as características "maternais" da sua religiosidade baseada na figura de Nossa Senhora. Nanda acredita que "tomar consciência" destas particularidades culturais e explorá-las "para a Obra de Deus" são estratégias que diferenciam substancialmente o Raboni Ajaray dos outros grupos católicos, mas, também, de outras igrejas evangélicas que contam com missionários brasileiros. Além disso, Nanda e Senyta enfatizaram que tais estratégias "abriram oportunidades" para elas, permitiram maior facilidade para se deslocarem entre a Espanha e o Brasil e lhes concederam "mais respeito" como brasileiras e como imigrantes, tanto dentro quanto fora da Espanha. Esta afirmação nos permite concluir que os espaços de agência (GIDDENS, 1984) destas mulheres brasileiras foram expandidos devido ao seu trabalho missionário. Neste contexto, a expansão dos espaços de agência nas vidas destas missionárias é circunscrito por reciprocidades religiosas ligadas à noção de dádiva (MAUSS, 1974).

Embora seja um trabalho voluntário, a participação na condução das atividades do Raboni Ajaray concedeu aos oito membros deste grupo de oração a possibilidade de fazer cursos profissionalizantes, de conseguir novos contatos de trabalho (dentro e fora da Espanha), ou aumentos dos seus respectivos salários, o que acarretou um maior poder de compra e, com isso, adquiriram um certo respeito e visibilidade no contexto do catolicismo barcelonês. Tais fatores 
trouxeram mudanças significativas na vida destes oito missionários e, para eles, essas conquistas são "uma graça de Deus”.

Não por acaso, a missionária Joana falou sobre a sua trajetória como imigrante em Barcelona, estabelecendo uma evidente associação entre o seu envolvimento religioso e a aquisição, através da esfera do consumo, do que chamou de "cidadania". Nesse sentido, parece que, se interpretadas enquanto estratégias de sobrevivência e integração social, as práticas missionárias de Joana e outros/as imigrantes brasileiros/as parecem ser construídas a partir de formas de subjetivação que, do ponto de vista sócio-antropológico, podem ser analiticamente associadas aos circuitos de dádiva sacrifical, amical e clientelista (MAUSS, 1974), à ideia de Capitalismo de Consumo (TRUMBULL, 2006) e, também, aos consequentes sentimentos utilitaristas e de "neoliberalização" da vida social que estes fatores comumente promovem. ${ }^{6}$

Este aspecto é muito importante para a compreensão das dinâmicas religiosas e às estratégias relacionadas ao gênero dos/as missionários/as brasileiros/as em Barcelona, e isso diz respeito não apenas ao Raboni Ajaray, mas também à evangélica Família Unida.

\section{A "masculinizada" IURD-Familia Unida}

Em Barcelona, num dos nossos dias de trabalho de campo sobre a IURDFamilia Unida, 20 de janeiro de 2012, numa sexta-feira, fomos mais uma vez ao Templo de San Andreu; era um culto especial, uma 'sessão espiritual do descarrego’. Estavam 13 pessoas presentes: onze mulheres e dois homens. O pastor Sérgio convidou todos os presentes para a oração inicial no altar. Perguntou como os fiéis estavam se sentindo após participarem da oração. A fiel Norma foi a única que disse que ainda estava sentindo um "peso sobre as costas”. O pastor lhe disse

\footnotetext{
${ }^{6}$ Estas possíveis associações analíticas são mais detalhadas e problematizadas em outros textos de nossa autoria que abordam a presença de missionários/as brasileiros/as na União Europeia (RODRIGUES; SILVA, 2015; SILVA; RODRIGUES, 2013).
} 
que aquele "peso" era um sinal de que um mal estava agindo em sua vida. Assim que recebeu uma nova oração do pastor sobre a sua cabeça, Norma manifestou um violento estado de "possessão demoníaca”.

O pastor Sérgio estava gripado e convocou a obreira brasileira Suelen para executar o exorcismo. Norma manifestava uma entidade masculina que se autodenominava "Exu das almas" e começou a se debater no chão de uma forma bem agressiva. Suelen dispensou a ajuda de um obreiro e continuou o exorcismo sozinha. Demonstrando muita força física e muito "trato" para lidar com a possessão, ela dominou totalmente a situação, finalizando o exorcismo da seguinte maneira: “Acabou pra você, satanás! Você vai ser queimado agora, queimado em nome de Jesus!”. Norma caiu desacordada no chão; enquanto recobrava a consciência, agradeceu a Suelen, a quem, nesta modalidade de guerra espiritual, Norma chamou de "um soldado de Deus".

No fim do culto, diversas pessoas foram parabenizar Suelen e ela, comentando a sua performance, falou que via com naturalidade o fato de ter "agido como um homem". Norma disse que, no momento da possessão, estava semiconsciente e que sentia Suelen não como uma mulher, mas como um "macho". Nesta específica situação de exorcismo, a evangélica Suelen não via como um problema o fato de ser considerada um "homem": "Eu esqueço que eu sou uma mulher. Eu atuo como um instrumento de Deus, um soldado de Deus”. Portanto, embora seja uma mulher, Suelen define a si própria como um "soldado", uma figura masculinizada. Neste contexto, as obreiras da IURD devem atuar "como homens", não apenas em termos de disciplina e força física, mas, principalmente, com uma “personalidade masculina”. Este exorcismo praticado por Suelen não constituiu um caso isolado neste contexto específico. Durante nossas pesquisas etnográficas na Catalunha, era comum ver obreiras realizando exorcismos nos templos da IURD-Familia Unida. Percebemos ainda que a maioria das pessoas possessas eram mulheres, porém que os exorcismos eram praticados prioritariamente pelos pastores. Entretanto, em muitos casos, ocorriam possessões simultâneas durante os cultos e, nessas ocasiões, todos os obreiros presentes eram 
convocados a intervir e expulsar os demônios, independentemente de serem homens ou mulheres.

É comum Suelen e as outras mulheres obreiras que atuam nos templos da Familia Unida de Barcelona utilizarem termos de registro militar para se referirem aos seus trabalhos: "Eu estou esperando uma ordem do pastor"; "Amanhã nós teremos um treinamento para nos aperfeiçoar na guerra espiritual"; e "O comandante [pastor] disse pra gente chegar duas horas antes do culto do domingo de manhã pra arrumar e limpar as coisas”.

Marta - uma outra missionária brasileira - disse que as outras igrejas evangélicas que existem no Brasil e na Espanha são "fracas" e "ineficazes" justamente porque elas não possuem a "força" e a "masculinidade" da IURD: “ Aqui na igreja, nós não temos sexo, não tem isso de obreiros homens e obreiros mulheres. Existem só obreiros que são como soldados fiéis sempre prontos para servir a nosso Senhor Jesus Cristo aqui na sua casa e sob as ordens do comandante [pastor]”.

A presença de catalães e espanhóis nos três templos da Família Unida é bastante reduzida. Durante nossas pesquisas nos templos de San Andreu e no Templo Central de Plaza España, encontramos apenas três "nacionais" que frequentavam com certa regularidade as atividades da igreja e todos estes três iam ao Templo Central. A catalã Drica (nascida em 1962) e o casal Joan e Paulina (ambos nascidos no Principado de Astúrias em 1978 e 1979, respectivamente) eram estas três pessoas. Drica nos relatou que foi pela primeira vez à Familia Unida com certo receio, mas que logo no primeiro culto ficou positivamente impressionada com a organização da igreja: recursos tecnológicos, design do templo, limpeza, pontualidade, vestimenta dos pastores e obreiros/as, entre outros fatores. 7 
Após se casarem em 2009, Joan e Paulina vieram para Barcelona, pois Joan, que trabalha em uma empresa multinacional, foi transferido para o escritório catalão desta empresa. Eles disseram que estão "conhecendo" a Familia Unida e que, apesar de estranharem um pouco a "mistura" de muitos elementos da liturgia, estão cada vez mais firmes na fé. Para Joan, a Familia Unida só não cresce mais entre os espanhóis como ele em virtude da sua ênfase nas ofertas pecuniárias e nos ideais de que as "graças” só serão alcançadas pelos fiéis através de sacrifícios financeiros. Para este interlocutor, tal ênfase está presente em outras igrejas evangélicas que ele conheceu no território espanhol, mas não de uma maneira tão acentuada como na Familia Unida.

De acordo com o Joan, a famosa frase "Yo no creo en brujas, pero que las hay, las hay" (Eu não acredito em bruxas, mas que elas existem, existem) ${ }^{8}$ ajuda a explicar alguns pontos da espiritualidade espanhola em geral e catalã em particular. Segundo este interlocutor, embora seja "mais presente" nas pessoas idosas, mais "provincianas" e no interior do país, esta espiritualidade é fortemente marcada pelas noções de magia e esoterismo e este aspecto faz com que um asturiano como ele, quando visite a IURD/Familia Unida, não sinta tanto "estranhamento" quanto, por exemplo, sentiria um sueco ou um polonês que visitasse esta igreja. Falando sobre relações de gênero, Joan comentou que o caráter "masculinizado" dos pastores e obreiros/as da Família Unida é interessante num país como a Espanha, onde a "praga do feminismo" destruiu a "família tradicional" e as relações de gênero hierárquicas que, na sua opinião, devem continuar existindo entre homens e mulheres. Ele terminou a conversa dizendo que as mulheres espanholas foram prejudicadas por interpretações equivocadas do feminismo e, por conta disso, algumas delas teriam se tornado "homens sem falo".

\footnotetext{
${ }^{7} \mathrm{Na}$ nossa etnografia sobre a presença da IURD na Europa, percebemos que cursos preparatórios e de treinamento contínuo para seus obreiros e pastores são, dentre outras, iniciativas que fazem com que a IURD se diferencie das demais igrejas protestantes em geral e pentecostais em particular, que existem no território destes citados países. Em sua dissertação de mestrado em Administração, defendida na Fundação Getúlio Vargas, Paulo José Pereira de Resende (2006) comenta que é possível observar na IURD os indícios de uma estratégia organizacional tal como as que são observáveis nas empresas públicas e privadas e que este perfil diferenciado da igreja, marcado pelo isolamento, pela ousadia e pelo cuidadoso planejamento de suas ações, certamente constituem os principais fatores que explicam o seu sucesso financeiro e o seu crescimento em número de fiéis, tanto dentro quanto fora do Brasil nos últimos anos.

${ }^{8}$ Frase cunhada por Miguel de Cervantes em seu clássico Dom Quixote de La Mancha.
} 
Estas percepções acima mencionadas por Drica e Joan (e também por outros/as interlocutores/as) dizem respeito a uma importante dimensão do gênero nos contextos de migração: a reavaliação de normas internalizadas de comportamento e o questionamento dos modelos de papéis sociais (RIEKER, 2011). No caso específico de imigrantes e missionários/as brasileiros/as, isso também se refere ao restabelecimento dos marcadores identitários comumente associados para caracterizar o que seria a "brasilidade” (PISCITELLI, 2009).

Acreditamos que em cada contexto social específico é importante investigar se a migração, o gênero e a religião possuem autonomia e dinâmicas próprias ou se elas fazem parte do mesmo sistema de diferenciação social. Outra questão importante é como estas três categorias estão articuladas na construção social do gênero, no contexto da imigração e entre os diversos grupos étnicos e religiosos (BARBIERI, 1992). No contexto particular dos/as missionários/as brasileiros/as em Barcelona, este argumento é bastante relevante, pois é imprescindível atentar para as possíveis dissonâncias de poder, para as cosmologias diferenciadas e para os distintos "status" que envolvem as relações destes/as próprios/as missionários/as e as relações destes/as com os fiéis que participam das atividades litúrgicas do Raboni Ajaray e da Família Unida: relações que são circunscritas por ideais de conversão, doutrina, interpretação e diálogos interculturais.

Outra importante questão é que os/as missionários/as do Raboni Ajaray e da Família Unida, especialmente as mulheres, desenvolvem práticas transnacionais através de comunicações constantes e visitas regulares ao Brasil, assim como através de remessas de dinheiro, informações e bens materiais. De acordo com Adriana Piscitelli (2009), para compreender estas práticas, é preciso uma perspectiva analítica que considere os diversos espaços de agência destas imigrantes, presentes em diferentes locais. Ou seja, seria reducionista refletir sobre as dinâmicas do empoderamento/desempoderamento na vida destas brasileiras como considerando apenas, de uma maneira isolada, a realidade nas quais elas vivem na Espanha: é mais profícuo contemplar a lógica da translocalidade, pois 
ela permite dar conta, por exemplo, das tentativas de exercer a maternidade à distância e das influências e participações destas mulheres nos cotidianos de suas famílias que permaneceram no Brasil, através de ações como remessas regulares de dinheiro e diálogos constantes por meio de dispositivos tecnológicos que permitem comunicações pela internet.

$\mathrm{Na}$ nossa etnografia coletamos testemunhos que falam a respeito de "novos status" e do que podemos sociologicamente chamar de "novas" agências (GIDDENS, 1984) que essas mulheres adquiriram com base nesses trabalhos missionários. Emblemático, por exemplo, foi o caso da obreira evangélica Suelen. Após sua chegada na Espanha e após ter se "especializado" como uma missionária da Família Unida, ocorreram duas importantes mudanças em sua vida: ela passou a "ser mais ouvida" nos problemas que envolvem seus familiares que ficaram no Brasil (em virtude, segundo ela, das remessas regulares de dinheiro que envia) e também passou a ser conhecida em sua cidade natal como uma "curadora", que já chegou a realizar "trabalhos de cura e libertação" de amigos e familiares no Brasil, a partir de Barcelona, através de chamadas telefônicas e de orações mediadas pelas telas dos computadores.

Ou seja, seria reducionista refletir sobre as estratégias de organização social, circunscritas pela dimensão do gênero, na vida destas missionárias pentecostais, considerando apenas as mudanças que ocorreram no contexto da diáspora. É importante considerar também as dinâmicas e as mudanças promovidas por estas mulheres nos seus locais de origem, das novas realidades das suas vidas e das novas capacidades de agência que lhes foram concedidas pelos fluxos migratórios e pelos respectivos contatos transnacionais e circulação de informação que tais processos provocam e potencializam.

As remessas regulares de dinheiro e bens materiais lhes permitem uma interferência regular nas vidas dos seus parentes no Brasil, que recebem estas “ajudas”, o que ocasiona uma ampliação dos espaços de influência e tomada de decisões por parte destas mulheres nas dinâmicas familiares e domésticas de suas 
respectivas localidades de origem no Brasil (PISCITELLI, 2009). Nesse sentido, tais remessas ultrapassam a esfera da afetividade e adquirem uma dimensão política e econômica, no sentido de que expandem, significativamente, os espaços de agência. Esta realidade reflete o caráter dinâmico, processual e transnacional das estratégias de gênero que são articuladas pelos/as missionários/as brasileiros/as e evidencia como os diferentes espaços de agência, estruturados pelos imigrantes, podem ser reconfigurados e expandidos pela esfera religiosa, seja ela protestante-evangélica ou católica-carismática.

\section{4 "Rebeldes", "inconstantes" e "membros fiéis": dinâmicas religiosas e identidades de gênero}

Para compreender as dinâmicas estratégias de organização social de ambos os grupos, o carismático Raboni Ajaray e a evangélica Família Unida, e o papel que a dimensão do gênero representa nestes processos, é importante refletir sobre as três categorias analíticas (êmicas) - que foram criadas pelos próprios membrosfiéis - com o intuito de definir suas composições e suas fronteiras internas e de apresentá-las para as pessoas "de fora": os rebeldes, os afastados ou inconstantes e os membros fiéis:

Os 'rebeldes' são pessoas que, por algum motivo, questionam a doutrina do grupo ou da igreja e que, por isso, visitam as reuniões apenas esporadicamente ou para acompanhar algum familiar.

Os 'afastados' ou 'inconstantes' são aqueles que começaram a frequentar as atividades religiosas e depois abandonaram. Caracterizam também os que apenas "ocupam cadeiras" no templo; isto é, são pessoas que "ainda não aceitaram Jesus de verdade" e que, por isso, embora possam estar fisicamente presentes nos cultos, são "inconstantes na fé" ou encontram-se espiritualmente "afastadas" destas atividades e, consequentemente, “do Espírito Santo”. 
A última categoria, a dos que se tornaram 'membros fiéis', designa aqueles que "receberam o Espírito Santo" e que, apesar das adversidades cotidianas e das "tentações do diabo", continuam firmes nos seus respectivos grupos religiosos.

Entre os considerados 'rebeldes' evangélicos estava uma mulher chamada Selma. Logo no primeiro culto que participou no Templo de San Andreu da Família Unida, com a sua mãe, ela se sentiu mal e, por conta disso, recebeu no altar uma oração personalizada do pastor. Durante a oração, ela vomitou o que depois chamou de "comida macumbada" e, nesta lógica, expeliu o mal espiritual que havia dentro de si. É importante realçar que esta fiel e a sua família frequentavam a Umbanda no Brasil.

A mãe de Selma, Lúcia, “permanecia firme na fé”. Contudo, encorajada pela sua filha, Lúcia se tornou uma "rebelde" e começou a criticar a IURD-Familia Unida, especialmente a sua exagerada ênfase na extração de dinheiro dos seus fiéis. Em março de 2012, Lúcia deixou esta igreja e começou a participar dos cultos da pentecostal "Igreja Batista Renovada (IBR)". De acordo com Lúcia, os pastores da IBR são muito diferentes, não são mercenários e as mulheres ocupam posições de liderança (não apenas como obreiras, mas também como pastoras, inclusive), "sem deixar de lado a feminilidade", fator que, em sua opinião, ocorreria na IURD. Enfatizou que o termo "homens de saias" descreve bem as atitudes e os comportamentos das obreiras desta igreja. Para elas, as obreiras Suelen e Marta, por exemplo, se moldaram a tal ponto à estrutura machista da IURD que teriam perdido as suas "almas femininas”.

Outro fiel "rebelde" era o mineiro Lucas. Pelo fato de ter laços de amizade com um dos etnógrafos, Lucas confidenciou que era gay. Disse ainda que tenta, mas que não consegue "se firmar" na Família Unida, devido às contradições desta igreja em relação ao gênero e à sexualidade. Os pastores e os/as obreiros/as frequentemente falam sobre a importância de cada fiel ser livre na "família de Cristo" (através do preceito de que "Deus ama todo mundo”) e desenvolver uma “fé racional”. Costumam ainda atribuir razões espirituais para qualquer problema 
(físico, emocional/psicológico ou econômico) ou para qualquer tipo de prática ou orientação sexual que não se enquadre dentro da heteronormatividade; por isso, consideram a homossexualidade como algo "maligno", um "comportamento desviante". Lucas comentou que este posicionamento contraditório faz com que esta igreja seja um pouco "irracional" e que, por essa razão, ele seja um fiel "confuso", que sente dificuldade em aceitar sua orientação sexual e que, constantemente, se interroga sobre se a homossexualidade seria uma doença ou a manifestação de um espírito maligno. Contudo, embora questione e critique alguns pontos de uma doutrina que o deixa "confuso e com dúvidas", Lucas disse que não consegue deixar de ser um fiel da Família Unida, ainda que um fiel "rebelde”.

Este caso revela o caráter contraditório sobre o qual está subsumida a cosmologia da IURD. Tentando ser “camaleônica”, adaptável em seu discurso e ritualidades, acaba se tornando também ambígua em sua doutrina, em suas atividades e em suas orientações e estes fatores se refletem significativamente na construção social das identidades de gênero dos seus fiéis. A ambiguidade é uma característica de diversos sistemas religiosos e, no caso da IURD, esta pode ser vista como uma das suas marcas. No caso específico de Lucas, esta ambiguidade emerge do fato de que, embora os discursos dos pastores apontem para uma significativa valorização do que chamam de "racionalidade", estes mesmos pastores continuam associando a homossexualidade a uma enfermidade, ignorando que a OMS (Organização Mundial da Saúde) ratificou a despatologização da homossexualidade em 17 de maio de 1990. Ou seja, embora discursivamente se apresente como uma igreja "racional" e que se encontra "antenada com a ciência", a IURD, em suas práticas cotidianas, contempla e valoriza apenas os aspectos "racionais" e "científicos" que são convenientes aos seus interesses e aos seus discursos extremamente conservadores, sobretudo àqueles que dizem respeito à sexualidade.

No templo de San Andreu, existem ainda outros/as onze fiéis "rebeldes", sete mulheres e quatro homens: uma destas mulheres se chamava Carmem. Sua 
trajetória religiosa dentro da Família Unida revela claramente o caráter dinâmico que pode circunscrever as três categorias êmicas acima mencionadas. Ela não se sentia uma fiel "inconstante", ainda que os pastores e obreiros/as sempre insistissem em dizer que ela era uma fiel, mas ainda não era uma "filha de Deus", pelo fato de não pagar o dízimo, não participar das correntes ${ }^{9}$ e, por esta razão, ainda não haver recebido o Espírito Santo. Na IURD, existe uma ação que "materializa" a confirmação de um/a participante como um/a "membro fiel": a inscrição do seu nome no "Livro dos Dizimistas".

Figura 3: 0 "Livro dos Dizimistas" (Templo de San Andreu).

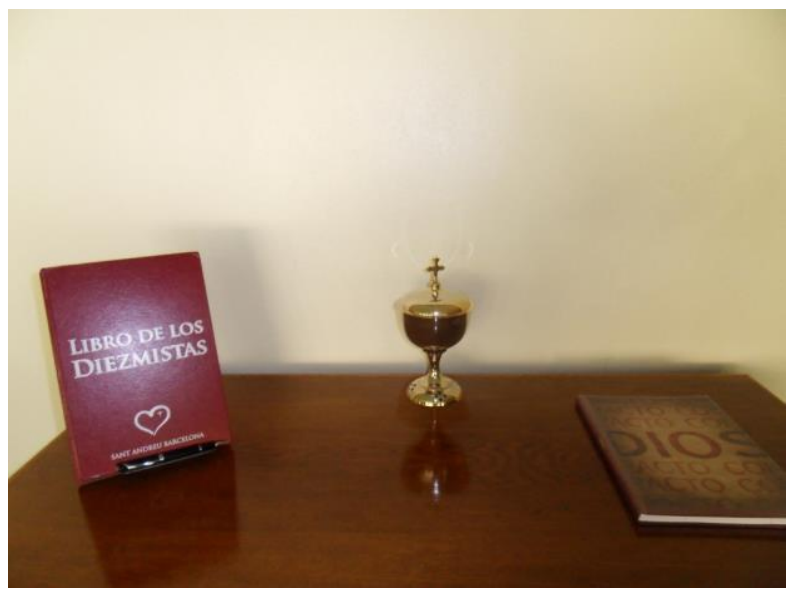

Fonte: Foto do autor (Donizete Rodrigues).

Falando sobre sua trajetória religiosa, Carmen disse que no começo não compreendia a liturgia e, por isso, considerava a doutrina da IURD como "machista", que reforçava os papéis desiguais entre homens e mulheres. Contudo, com o passar dos dias nos rituais da igreja, ela mudou de opinião e passou a perceber os "elementos positivos" como "força e credibilidade". Para Carmen, os grupos carismáticos católicos que ela conheceu, tanto na América do Sul quanto na

\footnotetext{
${ }^{9} \mathrm{O}$ calendário litúrgico da IURD é composto por "correntes" regulares que consistem em novenas que visam atuar em áreas específicas da vida do fiel e resolver questões, tais como: dificuldades financeiras, problemas de saúde, "libertações espirituais" e conflitos afetivos e familiares, dentre outros. Por exemplo: "Corrente da Prosperidade econômica", "Pacto com Deus pela Felicidade Amorosa" ou então "Corrente das mães desesperadas".
} 
Espanha, eram “espiritualmente fracos” e que só uma igreja “forte” como a IURD poderia ajudá-la no seu difícil processo de “mudança de mentalidade” e liberação "física e espiritual" que ela necessitava para continuar lutando como uma mulher imigrante num país como a Espanha.

Carmen possui uma interessante trajetória religiosa: quando tinha 5 anos de idade fora oferecida por seu pai a um xamã na Bolívia e, desde então, possui o "exu da morte" dentro de si. Para ela, essa era a razão do seu nervosismo, das suas dores de cabeça constantes e da sensação de "peso nas costas" - problemas para os quais disse não ter encontrado solução e nem melhora por meio da medicina alopáticocientífica.

Em cinco ocasiões, presenciamos Carmen manifestar seu "exu da morte" nas sessões espirituais do descarrego do templo da Familia Unida de San Andreu e sempre, após recobrar a consciência, ela ouvia do pastor Roberto que ainda não estava completamente livre daquele demônio, pelo fato de ser "inconstante" e de não ter tomado uma decisão definitiva de se tornar um membro fiel na igreja: "Deus é justo! Se você quer uma libertação completa, definitiva, deve se entregar plenamente e fazer um voto de fé, de sacrifício neste próximo domingo!”.

Uma semana depois, tivemos a oportunidade de conversar com Carmen sobre o ocorrido e ela comentou que aquelas palavras do pastor lhe encheram de coragem para "tomar uma atitude de fé". E qual foi esta "atitude de fé?” Ao sair da igreja naquela tarde, passou no banco e sacou todo o dinheiro que tinha na poupança, mas sem falar na quantia. No domingo seguinte, 5 de fevereiro, Carmen fez um "voto de fé com Deus": se dirigiu ao altar da igreja e ofereceu todo aquele dinheiro a Deus e sentiu ter recebido o Espírito Santo. A partir daquele momento, Carmen disse que deixou de se considerar e de ser considerada (pelo pastor, pelos obreiros e pelos demais membros da igreja) como uma fiel inconstante. Além disso, afirmou ter deixado de ser "dominada" por seu companheiro e por sua irmã e que passou a exercer mais autoridade sobre seus dois filhos e a encarar o mundo 
de uma maneira diferente, não mais como uma "coitadinha que aceita tudo", mas como uma "nova mulher": saudável e com forças para lutar e vencer, dona do seu próprio destino.

Carmen demonstrou estar bem consciente do caráter mercantilizado e de “consumo religioso" que a IURD promove - ainda que, obviamente, não tenha utilizado estes termos sociológicos. Algumas críticas, que são recorrentes na mídia, que costumam associar as doutrinas neopentecostais, nomeadamente no caso da IURD, a uma lavagem cerebral, que aliena as pessoas (especialmente as mulheres), parece que, além de reducionistas, não adquirem respaldo de realidades sociais como a que observamos nas nossas etnografias em vários países europeus (RODRIGUES; SILVA, 2015) e de outras realidades sociais, como as que foram estudadas por Campos (1995) e Machado (1996) no Brasil.

Bastante emblemática é a afirmação de Carmen, de que ela se tornou "saudável e mais forte como mulher e como imigrante" após se tornar um "membro fiel" da Familia Unida. O acompanhamento que fizemos do cotidiano litúrgico dos seus templos em Barcelona permite-nos afirmar que, nessa cidade, a IURD-Família Unida é uma igreja que incentiva muito o empreendedorismo, a ideia de reciprocidade entre seus fieis e também o preceito de que o enriquecimento e o consumo (de bens materiais caros) é um meio eficaz para se alcançar a "cidadania" e o "bem-estar social" (moradia, educação e saúde) em países em "profunda crise econômica e moral” e com "avançado neoliberalismo" como, segundo os pastores da igreja, é o caso de Espanha.

Não por acaso, Carmen se tornou uma pequena empresária desde que aprendeu na IURD de Barcelona que "é dando que se recebe" e que explorar as suas "ganas por prosperidad" (vontade de prosperar) seria algo "bom, saudável e divino". Esta interlocutora nos relatou que vem "subindo na vida", adquirindo bens materiais e percebemos que ela associa o seu atual "bem-estar" ao fato de poder consumir "coisas caras e de valor" e não apenas "coisas utilitárias". Antes de uma das reuniões da prosperidade econômica no Templo de San Andreu, ocorrida em 
23/01/2012, Suelen sintetizou bem essa noção para uma nova fiel que estava na igreja pela primeira vez:

Deus quer sempre o melhor pra gente, quer que a gente tenha um bom carro, uma boa casa, dinheiro no banco. Isso é cidadania, e isso nenhum governo, nenhum político vai dar pra nós. Só quem pode dar isso pra nós é ele ó [aponta para o nome de Jesus no altar da igreja].

Um ponto a ser salientado é que Carmen só se tornou uma pequena empresária (sócia de uma microempresa) porque ficou mais próxima de outra fiel boliviana, que já era sócia de uma microempresa de venda de cosméticos. A aproximação entre as duas só ocorreu porque Carmen, como já dissemos, deixou de ser vista na igreja como uma "afastada/inconstante" e se tornou "membro fiel".

Nossos dados etnográficos demonstram que as estratégias de organização social e de gênero permitem a dinâmica articulação de novas formas de agência que são baseadas nas lógicas de reciprocidade do dom (MAUSS, 1974) e que também estão ligadas à noção de capitalismo de consumo (TRUMBULL, 2006), um processo claramente evidente na IURD, uma instituição religiosa que possui a seu favor um aparato midiático gigantesco dentro e fora do Brasil. No caso da Espanha, este aparato funciona, sobretudo, através da "IURD TV" (um canal que funciona 24 horas por dia e que pode ser acessado livremente pela internet) e também através da Rede Record de televisão - cuja programação pode ser assistida gratuitamente em todo o território espanhol - que dedica parte da sua programação à divulgação de programas da IURD. Vários fiéis latino-americanos

disseram que, primeiramente, conheceram o trabalho da IURD-Família Unida através da IURD TV na internet ou por alguns programas da Rede Record e que, posteriormente, visitaram a Igreja e se tornaram fieis. 


\section{Conclusões}

Seguindo as sucessivas críticas da divisão (hetero)sexual do trabalho conduzidas pelo feminismo, estudos de gênero, teoria queer - e, particularmente, com base em nossas próprias pesquisas etnográficas, acreditamos que a Virgem Maria (Theotokos, mãe de Jesus) e, consequentemente, "mãe de todos os/as católicos/as", é uma figura-chave para os processos de "feminilização" no contexto religioso católico. As diferentes epifanias da Mariologia - tais como a Virgem de Guadalupe, Fátima ou Nossa Senhora Aparecida - são elementos cruciais que influenciam as percepções de feminilização entre o carismático Raboni Ajaray. No Protestantismo, diferentemente, a ausência de uma forte Mariologia é uma fonte para a ênfase no "Deus como Pai” e como um(a) “(figura masculina) forte”. E essa é a base do discurso e do corpus dogmático da evangélica IURD-Família Unida.

Assim, estes fatores influenciam significativamente na forma como os imigrantes, latino-americanos em geral e os brasileiros em particular, percebem as relações de gênero que são circunscritas pela esfera religiosa e a vivenciam diferenciadamente em seus específicos contextos migratórios. Os/as missionários/as brasileiros/as tiveram que "reconfigurar" o que eles/as achavam que era apropriado para homens e para mulheres no Brasil e adaptar tais percepções prévias às novas realidades sociais nas quais estão inseridos/as. Neste sentido, o caráter "feminilizado" do Raboni Ajaray e o "masculinizado" da Família Unida são categorias êmicas de gênero, dinamicamente construídas por estes/as missionários/as.

No caso da evangélica Familia Unida, o aspecto religioso "masculinizado" é associado ao seu caráter dinâmico, polissêmico e "camaleônico", características vistas como positivas e elementos cruciais para explicar o forte poder de atração de novos fiéis, imigrantes brasileiros e outros e também integrantes da sociedade anfitriã. 
O jeito "maternal” e o caráter "feminilizado" do Raboni Ajaray constituem elementos de identidade cultural e de gênero que são cruciais para caracterizar os carismáticos e, também, a legitimidade dos/as missionários/as entre os/as fiéis deste grupo de oração católico. Esta legitimidade, para parafrasear Giddens (1984), amplia os espaços de agência e a habilidade de interferir nas estruturas sociais e nas estratégias de gênero da população imigrante, especialmente as mulheres.

As trajetórias de vida das mulheres carismáticas e evangélicas analisadas sugerem que elas sentem a si próprias como mais empoderadas, particularmente em algumas esferas da vida social (trabalho, inserção em redes de confiança e reciprocidade, que lhes garantem novas oportunidades econômicas) e, psicologicamente, com a melhoria da autoestima. Esta ideia de empoderamento se deve ao sentimento de communitas (TURNER, 1969) e à construção de reciprocidades ligadas ao dom (MAUSS, 1974), ambos processos estimulados pelos vínculos religiosos que são articulados a partir das atividades do carismático Raboni Ajaray e especialmente da evangélica Família Unida.

Os dados etnográficos demonstraram que a análise das dinâmicas estratégias de organização social, em ambos os grupos religiosos, é relevante para compreender e contextualizar as três categorias êmicas: os "rebeldes", os "inconstantes" e os "membros fiéis": como vimos, "rebeldes" são as pessoas que criticam a doutrina da igreja/grupo e que, por isso, não participam continuamente dos rituais; “inconstantes" é um termo ambíguo, já que designa tanto as pessoas que deixaram definitivamente a igreja/grupo quanto aqueles que, embora estejam fisicamente presente nas atividades religiosas, são consideradas "inconstantes na fé”, devido ao fato de não terem "aceitado Jesus verdadeiramente”; os membros fiéis são aqueles que permanecem constantes e firmes em seus respectivos grupos religiosos. 
Em relação às estratégias de gênero e de organização social, o cotidiano destes/as missionários/as brasileiros/as é circunscrito por dinâmicos processos que trazem consigo novas subjetividades, baseadas sobre formas específicas de reciprocidade, influenciadas pelo "capitalismo de Consumo". Em seu estudo, Marylin Strathern (1988) inclui a dimensão do gênero para compreender melhor a noção de "dádiva”, em um contexto de diálogo intercultural. Isso está bem evidente na Família Unida e no Raboni Ajaray, onde as doutrinas e ritualidades refletem os processos de construção social de identidades de gênero entre os fiéis.

É relevante realçar que este estudo comparativo - focado na pertinente trilogia antropológica religião, migração e gênero - foi também conduzido seguindo a perspectiva analítica da "reverse mission" (FRESTON, 2010). Este ponto de vista revela não apenas as estratégias de gênero e a interculturalidade de um grupo de oração carismático e de uma igreja evangélica de origem brasileira num contexto diaspórico, mas também processos de mudança social e religiosa na Europa. Antes exportador de doutrinas e instituições religiosas, a secularizada Europa é hoje um território fértil para o trabalho missionário originário da América Latina e do Brasil, em particular.

O reavivamento religioso do "Norte" (Europa), desenvolvido por missionários do "Sul" (América Latina) é um processo dinâmico e em forte expansão. Portanto, a Europa constitui hoje um enorme campo etnográfico para sociólogos e antropólogos interessados em pesquisar sobre diferentes grupos religiosos pentecostais (católicos-carismáticos e protestantes-evangélicos), nas suas diversas formas de adaptação e diálogo cultural com as sociedades anfitriãs, bem como as suas estratégias de proselitização, conversão e reavivamento religioso de nacionais europeus e de imigrantes. 


\section{REFERÊNCIAS}

BADET SOUZA, Maria. La Construcción del imaginario social de la mujer brasileña en España: análisis de la recepción mediática junto a estudiantes del $4^{\circ} \mathrm{ESO}$ de Barcelona, Sabadell y Sitges. 2011, 190 f., Tese (Doutorado em Ciências Sociais) Universitat Autónoma de Barcelona, Barcelona.

BARBIERI, Teresita de. Sobre la Categoría de Género. Una introducción teóricometodológica. Revista Interamericana de Sociología, México, v. 6, n. 2, p. 147-178, 1992.

BLÁZQUEZ, Ricardo Las Comunidades Neocatecumenales. Bilbao: Desclée, 2009.

CAMPOS, Roberta B. Carneiro. Emoção, magia, ética e racionalização: as múltiplas faces da Igreja Universal do Reino de Deus. 1995, Dissertação (Mestrado em Antropologia). Universidade Federal de Pernambuco, Recife.

COLEMAN, Simon. The Globalization of Charismatic Christianity: spreading the gospel of prosperity. Cambridge: Cambridge University Press, 2000.

FRESTON, Paul. Reverse Mission: A Discourse in Search of Reality? PentecoStudies, Birmingham, v.9, n. 2, p. 153-74, 2010.

FUENTES, Francisco Javier Moreno; CALLEJO, María Bruquetas. Inmigración y Estado de Bienestar en España. Barcelona: Obra Social "la Caixa", 2011.

GIDDENS, Anthony. The Constitution of Society: Outline of the Theory of Structuration. Cambridge: Polity Press, 1984.

GOFFMAN, Erving. Stigma: notes on the management of spoiled identity. New York: Simon \& Schuster, 1963.

KEATEN, James; SOUKUP, Charles. Dialogue and Religious Otherness: toward a model of pluralistic interfaith dialogue. Journal of International and Intercultural

Communication, v. 1, n. 2, p. 168-187, 2009.

LA UNIVERSAL en España: determinación, sacrificios y perseverancia. Disponible en: <http://www.universal.org.ar/la-universal-en-espana-determinacion-sacrificios-yperseverancia >. Acesso em: 12 maio 2015.

LÓPEZ, Emilio Parra; CORTINA, Manuel Suárez. El Anticlericalismo Español Contemporáneo. Madrid: Biblioteca Nueva, 1998.

MacHARG, Kenneth. Spain's Awakening: is revival around the corner for Spain? Latin American Missions, Valdosta, GA, 10-21. (report), 2008. 
MACHADO, Maria das Dores Campos. Carismáticos e Pentecostais: adesão religiosa e seus efeitos na esfera familiar. Campinas: Editora Autores Associados/ANPOCS, 1996.

MAUSS, Marcel. Ensaio sobre a dádiva: forma e razão da troca nas sociedades arcaicas. In Sociologia e Antropologia, Volume II. São Paulo: Edusp, 1974 [1923-24].

PÉREZ-AGOTE, Alfonso. Religious Change in Spain. Social Compass, Madrid, v. 57, n. 2, p. 224-234, 2010.

PISCITELLI, Adriana G. Tránsitos: circulación de brasileñas en el ámbito de la transnacionalización de los mercados sexual y matrimonial. Horizontes

Antropológicos, Porto Alegre, v. 15, n. 31, p. 101-137, 2009.

PLUSS, Caroline. Migration and the Globalization of Religion. In Peter Clarke (ed.), The Oxford Handbook of the Sociology of Religion. Oxford: Oxford University Press,p. 491-506, 2009.

RESENDE, Paulo José Pereira. Igreja Universal do Reino de Deus: análise de um caso de sucesso de estratégia por diferenciação. 2006, 100f. Dissertação (Mestrado em Admistração Pública). Fundação Getúlio Vargas, Rio de Janeiro.

RIEKER, Yvonne. Love Crossing Borders: changing patterns of courtship and gender relations among Italian migrants in Germany”. In: BALDASSAR, Loretta; GABACCIA, Donna (Ed.). Intimacy and Italian Migration: Gender and Domestic Lives in a Mobile World. Fordham: Fordham University Press, 2011, p. 113-125.

RODRIGUES, Donizete; SILVA, Marcos de Araújo. Dinâmicas do Pentecostalismo Brasileiro na Europa: o caso da IURD em Portugal, Espanha, Irlanda, Itália e Alemanha. In Ari Pedro Oro \& Donizete Rodrigues (eds.), Transnacionalização Religiosa: religiões em movimento. Porto Alegre, Editora CirKula, 2015 (no prelo).

SANTIAGO, José. La dimension conséquentielle et la nouvelle pluralité religieuse de l' Espagne actuelle. Social Compass, Madrid, v. 57, n. 1, p. 3-14, 2010.

SILVA, Marcos de Araújo; RODRIGUES, Donizete. Religion, Migration and Gender Strategies: Brazilian (Catholic and Protestant) Missionaries in Barcelona. Religion and Gender, Utrecht, vol. 2, n. 2, p. 42-59, 2013.

STRATHERN, Marilyn. The Gender of the Gift: problems with women and problems with society in Melanesia. Berkeley: University of California Press, 1988.

TURNER, Victor. The Ritual Process: structure and anti-structure. Chicago: Aldine, 1969.

TRUMBULL, Gunnar. Consumer Capitalism: politics, product markets and firm strategy in France and Germany. Ithaca: Cornell University Press, 2006.

VELASCO, Francisco Díez de. Religiones en España: historia y presente. Madrid: Akal, 2012. 
VELHO, Otávio. Missionization in the Postcolonial World: a view from Brazil and elsewhere”. In Thomas J. Csordas (ed.). Transnational Transcendence: essays on religion and globalization. Berkeley: University of California Press, p. 31-54, 2009.

YANG, Fenggang; EBAUGH, Helen R. Transformations in new immigrant religions and their global implications". American Sociological Review, West Lafayette, v. 1, n. 66, p. 269-288, 2001. 